\section{International Scientific Journal Theoretical \& Applied Science}

p-ISSN: 2308-4944 (print) e-ISSN: 2409-0085 (online)

Year: $2018 \quad$ Issue: $01 \quad$ Volume: 57

Published: $30.01 .2018 \quad$ http://T-Science.org

SECTION 13. Geography. History. Oceanology. Meteorology.
Erkin Zuhriddinovich Nuriddinov

DH, Professor of Tashkent

State Pedagogical University named after Nizami, Uzbekistan

Azer Nadir ogli Adigezalov PhD Student in History of Uzbekistan of Andizhan State University named after Babur, Uzbekistan Azerbay23@mail.ru

Dilyor Kozimjon ogli Abidov student of Historical Faculty

Andizhan State University named after Babur, Uzbekistan

\title{
THE APPEARANCE OF NEW PARTICIPANTS OF MODERN INTERNATIONAL RELATIONS AND DISPOSAL CHANGE OF GEOPOLITICAL FORCES IN THEM
}

\begin{abstract}
The article deals with the data of cessation of the cold war, i.e. the ideological confrontation of the two superpowers of the USA and the USSR, as a result of this world politics changed from bipolar power distribution to a unified world system - globalization with the pluralism of opinions. In the end there were created conditions for liberal values' spreading in the world, relations between market economy and the western model of development, which had achieved the greatest success by that time. In such conditions a number of new independent states come to the world arena, becoming integral subjects of international relations.

Key words: Cold war, liberal values, market economy, the western model of development, new participants of international relations, globalization.

Language: Russian

Citation: Nuriddinov EZ, Adigezalov AN, Abidov DK (2018) THE APPEARANCE OF NEW PARTICIPANTS OF MODERN INTERNATIONAL RELATIONS AND DISPOSAL CHANGE OF GEOPOLITICAL FORCES IN THEM. ISJ Theoretical \& Applied Science, 01 (57): 117-125.

Soi: http://s-o-i.org/1.1/TAS-01-57-22 Doi: crossef https://dx.doi.org/10.15863/TAS.2018.01.57.22

\section{ПОЯВЛЕНИЕ НОВЫХ УЧАСТНИКОВ СОВРЕМЕННЫХ МЕЖДУНАРОДНЫХ ОТНОШЕНИЙ И ИЗМЕНЕНИЕ РАССТАНОВКИ ГЕОПОЛИТИЧЕСКИХ СИЛ В НИХ.}

Аннотация: В статье приводятся даннье о прекращении холодной войны, т.е. идеологического противостояния двух сверхдержав США и СССР, в результате чего мировая политика от биполярного расклада сил перешла к становлению единого миропорядка - глобализации, с плюрализмом мнений. В итоге, были созданы условия для распространения в мире либеральных ценностей, отношений рыночной экономики и западной модели развития, которые к тому времени добились наибольшего успеха. В этих условиях на мировую арену выходит целый ряд новых независимых государств, становясь неотъемлемыми субъектами международных отномений.

Ключевые слова: Холодная война, либеральные ченности, рыночная экономика, западная модель развития, новые участники международных отношений, глобализация.

\section{Введение}

Кардинальные перемены, происшедшие в мировом развитии на рубеже 1980-1990-х годов, co всей остротой поставили как перед исследователями, так и перед политиками вопрос о характере и закономерностях международных отношений. Падение Берлинской стены стало символом окончания холодной войны. Однако, вопреки оптимистическим ожиданиям некоторых идеалистически настроенных политиков и части

научной общественности, за ним последовали не сближение Востока и Запада на основе универсальных ценностей и не становление общемирового сообщества, основанного на принципах взаимопомощи и сотрудничества всех со всеми, а совсем иные события, во многом неожиданные как для практических политиков, так и для научного сообщества. Среди них распад СССР и возникновение на политической карте мира новых независимых государств, разрастание
\end{abstract}


этнических конфликтов и усиление сепаратистских тенденций на фоне роста глобальной взаимозависимости, приобретение международным терроризмом угрожающих масштабов, наконец, подрыв всей прежней структуры международной безопасности [1, с. 45].

При подходе к анализу новой системы международных отношений, видимо, следовало бы исходить из того, что окончание холодной войны завершило в принципе процесс оформления единого мирового сообщества. Путь, пройденный человечеством от изолированности континентов, регионов, цивилизаций и народов через колониальное собирание мира, расширение географии торговли, через катаклизмы двух мировых войн, массовый выход на мировую арену освободившихся от колониализма государств, мобилизацию противоположными лагерями ресурсов всех уголков мира в противостоянии холодной войны, повышение компактности планеты в результате научнотехнической революции, завершился, наконец, крушением «железного занавеса» между Востоком и Западом и превращением мира в единый организм с определенным общим набором принципов и закономерностей развития его отдельных частей. Мировое сообщество все больше становится таковым в реальности. Поэтому в последнее время повышенное внимание уделяется проблемам взаимозависимости и глобализации мира, общему знаменателю национальных составляющих мировой политики. Видимо, анализ этих трансцендентных универсальных тенденций и может позволить более достоверно представить направление изменения мировой политики и международных отношений.

\section{Появление новых участников международных отношений \\ В начале 90-х годов, если рассматривать мир} c точки зрения геополитики, карта мира претерпела серьезные изменения. Распад Варшавского договора, Совета экономической взаимопомощи положил конец зависимости государств Центральной и Восточной Европы от Москвы, превратил каждое из них в самостоятельного агента европейской и мировой политики. Распад Советского Союза в принципе изменил геополитическую ситуацию в евразийском пространстве. В большей или меньшей степени и с разной скоростью государства, образовавшиеся на постсоветском пространстве, в том числе, Узбекистан и Азербайджан, наполняют реальным содержанием свой суверенитет, формируют свои собственные комплексы национальных интересов, внешнеполитические курсы, не только теоретически, но и по существу становятся самостоятельными субъектами международных отношений.

C момента обретения независимости, Узбекистан проводит активную самостоятельную внешнюю политику, направленную на возрождение роли нашего государства в современном мире, прежде всего, из его геополитического положения и природноресурсных условий.

В Узбекистане производится стратегически важный продукт - хлопок, выращиваются зерновые культуры, развито овощеводство, шелководство, каракулеводство и другое ценнейшее сельскохозяйственное сырье в масштабах, необходимых не только для удовлетворения собственных потребностей, но и для поставок в другие страны. Республика обладает достаточным потенциалом, позволяющим защитить политическую и экономическую независимость Республики. Благоприятный климат, минерально-сырьевые ресурсы, большие запасы стратегических материалов и сельскохозяйственного сырья выводят Узбекистан в число богатейших стран региона и мира.

Площадь Узбекистана - 447,4 тысяч квадратных километров. Недра республики богаты ценнейшими минерально-сырьевыми ресурсами. Найдены практически все элементы известной периодической системы Менделеева. «Это дает возможность для осуществления глубоких структурных преобразований развития отраслей, которые обеспечат выход республики на мировой рынок» [2, с. 13].

Сегодня выявлено более 2700 месторождений и перспективных рудопроявлений различных полезных ископаемых, включающих около 100 видов минерального сырья, из которых, более 60 уже используются в народном хозяйстве.

По ряду важных полезных ископаемых, таких как золото, уран, медь, природный газ, вольфрам, калийные соли, фосфориты, каолины, Узбекистан по подтвержденным запасам и перспективным рудам занимает ведущие места не только в СНГ, но и во всем мире [3, с. 44-45].

Как известно, Узбекистан находится в самом центре Азиатского региона - в центральной и северной частях Центральной Азии Географическое расположение Узбекистана на перекрестке древних караванных и современных торгово-коммуникационных путей, с одной

После января 1993 года для обозначения Узбекистана, Казахстана, Кыргызстана, Таджикистана и Туркменистана, стал использоваться термин «Центральная Азия», как приемлемый для всех стран региона, вместо прежнего «Средняя Азия и Казахстан». 
стороны, делает очень выгодным геостратегическое положение страны, так как, именно Узбекистан, служит связующим звеном автономной энергетической и водной систем Средней Азии, играет все более активную роль в развитии отношений с зарубежными странами. С другой стороны, Узбекистан оказался самым отдаленным от морских портов государством, нашей республике для выхода к морским портам необходимо пересекать территории нескольких стран. Поэтому для полноценного вхождения Узбекистана в современную глобальноэкономическую систему необходимо участие республики в интеграционных процессах, способствующих использования потенциала страны не только в рамках региона, но и в мировых масштабах.

Выступая 10 мая 1998 года на международной конференции по развитию транспортного коридора Европа - Кавказ - Азия (ТРАСЕКА) Первый Президент Узбекистана подчеркнул, что «реализация проекта не только открывает исключительную возможность альтернативного, более устойчивого доступа стран, не имеющих выхода к морю, к трансевропейским и трансазиатским транспортным сетям, но и, сокращая транспортное плечо, открывает новые перспективы в расширении экспортных поставок, активизации взаимовыгодной внешнеторговой деятельности стран-участниц проекта» [4, с. 172].

Центральноазиатский регион с древности занимал важное место в геополитических процессах, находясь на перепутье трансконтинетальных торговых и культурных путей, не зря, еще в конце XIX - начале XX веков известный английский географ и геополитик Халфорд Маккиндер особо выделил Центральную Азию, как Hartland (середину мира), владение которой он рассматривал как основу мирового господства [5, с. 75-79].

Провозглашение 18 октября 1991 года своей независимости Азербайджанской Республикой, расположенной на важном геополитическом пространстве, а также произошедшие в конце 80х-начале 90-х годов в международной жизни изменения выдвинули на передний план исключительно важную задачу формирования и реализации нового, соответствующего принципам национальной государственности, внешнеполитического курса. Важное значение в укреплении независимости, защите государственных интересов Азербайджана приобретают его богатый экономический потенциал и благоприятная геополитическая позиция. Эти факторы создают хорошую основу для проведения эффективного и целенаправленного внешнеполитического курса, отвечающего интересам национальной государственности Азербайджана [6, с. 250-251].

Географические ресурсы Азербайджана составляют его территория в 86,6 тысяч квадратных километров, соединяющее Европу и Азию благоприятное геополитическое и геоэкономическое положение, транспортнокоммуникационные линии с выходом через Каспийское море в Россию, Центральную Азию, Иран, автомобильной и железной дорогами в Грузию и Черноморский регион, Иран, Турцию (с территории Нахчывана), Россию, Армению.

По географическим и территориальным ресурсам Азербайджан считается самым большим и благоприятным государством Южного Кавказа. Несмотря на то, что окружающая его геополитическая атмосфера (изза фактора Армении, Ирана и России) в некоторой степени ограничивает возможности проведения в полной мере независимой политики и свободу действия на международной арене в национальных интересах, что на Южном Кавказе и вокруг него существуют серьезные конфликты и между государствами региона не преодолены разногласия в вопросах безопасности, западной или восточной ориентации, все это не уменьшает значения выгодного географического расположения нашей страны.

Азербайджан считается воротами Евразии, центральным государством транспортнокоммуникационного и энергетического коридора Запад-Восток. В этом смысле Азербайджан выступает для России в роли соперника (альтернативы), а для стран Запада и Востока - связующей страной (мостом). Азербайджан является направляющей силой и одним из основных гарантов транспортнокоммуникационного проекта ТРАСЕКА по возрождению древнего Шелкового пути (это самый удобный и кратчайший коридор, открывающийся из Китая в Европу и на весь мир), стратегических нефтепровода БакуТбилиси-Джейхан и газопровода Баку-ТбилисиЭрзурум.

Как отмечал Общенациональный лидер Азербайджана Гейдар Алиев на Саммите тысячелетия в

Нью-Йорке 7 сентября 2000 года: «Азербайджан вносит свой вклад в позитивное развитие глобализации. Используя свое географическое положение, ресурсы и потенциал, имеющие геостратегическое значение мирового масштаба, моя страна эффективно реализует берущую начало в богатом историческом прошлом и ориентированную в будущее роль моста между Востоком и Западом. Мы вкладываем огромные усилия в восстановление Великого шелкового пути, создание 
транспортного коридора Европа-Кавказ-Азия, разработку и транспортировку на мировые рынки углеводородных ресурсов Каспийского бассейна. Эти проекты имеют решающее значение для свободного и полноценного развития государств нескольких регионов мира, они дадут толчок транснациональному сотрудничеству и окажут определяющее влияние на развитие глобальной обстановки» [7].

Кроме того, Азербайджан, участвующий также в транспортно-коммуникационном коридоре Южная Азия, Россия, Иран и Европа, еще раз подтвердил, что располагает благоприятными географическими ресурсами. В настоящее время Азербайджан, как одна из ключевых транзитных стран Евразийского региона, занимает важное место в ряду основных товарных, энерготопливных и других центров связей по линии Восток-Запад. Эта позиция все более укрепляется, и Азербайджан расширяет свои транзитные возможности. А самое главное основные центры глобализации и региональной интеграции (Европейский Союз, США, Япония, Китай, страны Юго-Восточной Азии и др.) заинтересованы в укреплении позиций Азербайджана как транзитной страны и прикладывают к этому серьезные усилия [6, с. 304-305].

Таким образом, Узбекистан и Азербайджан, с обретением государственной независимости, стали активными и неотъемлемыми участниками международных отношений, региональных и глобальных интеграционных процессов. Анализ внешнеполитической и геополитической деятельности двух государств, несмотря на относительную молодость, свидетельствует о зрелости их политической доктрины, соответствующей выработанным принципам и приоритетам международного права.

\section{Изменение геополитических сил}

Дробление постсоветского пространства на пятнадцать суверенных государств изменило геополитическую ситуацию и для соседних стран, ранее взаимодействовавших с единым Советским Союзом, например Китая, Турции, стран Центральной и Восточной Европы, Скандинавии.

Не только изменились локальные «балансы сил», но и резко возросла многовариантность отношений. Разумеется, Российская Федерация остается самым мощным государственным образованием на постсоветском, да и на евразийском пространстве. Но и ее новый, весьма ограниченный по сравнению с бывшим Советским Союзом потенциал, с точки зрения территории, населения, удельного веса экономики и геополитического соседства, диктует новую модель поведения в международных делах, если их рассматривать под углом зрения многополярного «баланса сил».

Геополитические изменения на Европейском континенте в результате объединения Германии, распада прежней Югославии, Чехословакии, очевидной прозападной ориентации большинства стран Восточной и Центральной Европы, включая государства Балтии, накладываются на определенное усиление европоцентризма и самостоятельности западноевропейских интеграционных структур, более рельефное проявление в ряде стран Европы настроений, не всегда совпадающих со стратегической линией США.

Динамика экономического усиления Китая и повышение его внешнеполитической активности, поиск Японией более самостоятельного, подобающего ее экономической мощи места в мировой политике вызывают подвижки в геополитической ситуации в Азиатскотихоокеанском регионе. Объективное возрастание удельного веса Соединенных Штатов в мировых делах после окончания холодной войны и распада Советского Союза в определенной степени нивелируется повышением самостоятельности других «полюсов» и определенным усилением изоляционистских настроений в американском обществе.

В новых условиях с окончанием противостояния двух «лагерей» холодной войны изменились координаты внешнеполитической деятельности и большой группы государств, входивших ранее в «третий мир». Потеряло свое прежнее содержание Движение неприсоединения, ускорилось расслоение Юга и дифференциация отношения образующихся в результате этого групп и отдельных государств к Северу, который также не монолитен.

Другим измерением многополярности можно считать регионализм. При всей разноплановости, неодинаковых темпах развития и степени интеграции региональные группировки вносят дополнительные особенности в изменение геополитической карты мира. Сторонники «цивилизационной» школы склонны рассматривать многополярность под углом зрения взаимодействия или столкновения культурно-цивилизационных блоков. По мнению самого модного представителя этой школы американского ученого С. Хантингтона, мир делится на следующие цивилизации: западная (европейская), конфуцианская, японская, исламская, индаистская, славяно-православная, латино-американская и африканская [8]. По его мнению, взаимодействие и конфликты будут происходить по данным признакам [9, с. 45].

Действительно, региональные процессы развиваются на разных цивилизационных фонах. Но вероятность принципиального деления 
мирового сообщества именно по этому признаку на данный момент представляется весьма умозрительной и пока не подкрепляется скольконибудь конкретными институционными или политикообразующими реалиями. Даже противоборство исламского «фундаментализма» с западной цивилизацией со временем теряет свою остроту.

Более материализованным является экономический регионализм в виде высокоинтегрированного Европейского союза, других региональных образований различной степени интеграции - Азиатско-тихоокеанского экономического сотрудничества, Содружества Независимых Государств, АСЕАН, Североамериканской зоны свободной торговли, аналогичных образований, зарождающихся в Латинской Америке и в Южной Азии.

Хотя и в несколько измененном виде, но сохраняют свое значение региональные политические институты, например Организация латиноамериканских государств, Организация африканского единства и т. д. Они дополняются такими межрегиональными многофункциональными структурами, как североатлантическое партнерство, связка США Япония, трехсторонняя структура Северная Америка - Западная Европа - Япония в виде «семерки», к которой постепенно подключается Российская Федерация.

После окончания холодной войны геополитическая карта мира претерпела очевидные изменения. Но, многополюсность объясняет скорее форму, чем суть новой системы международного взаимодействия. Означает ли многополюсность восстановление в полном объеме действия традиционных движущих сил мировой политики и мотиваций поведения ее субъектов на международной арене, характерных в большей или меньшей степени для всех этапов Вестфальской системы?

События последних лет пока не подтверждают такую логику многополюсного мира. Во-первых, Соединенные Штаты ведут

- Вестфальская система международных отношений система международных отношений, созданная после окончания Тридцатилетней войны в 1648 году. Этой системе присуща идея баланса сил. Признание в качестве одного из ключевых «принципа национального государственного суверенитета», когда каждое государство обладает всей полнотой власти на своей территории. Характерна деидеологизация, то есть устранение конфессионального фактора как одного из основных факторов политики. Межгосударственные союзы в новых условиях становились более гибкими и ситуативными. Смена партнёра по коалиции стала не таким уж редким явлением. Суть её сводилась к тому, чтобы политическим или дипломатическим маневром не позволить какому-либо одному европейскому государству или коалиции государств аккумулировать силы, значительно превосходящие мощь их вероятных соперников. себя значительно сдержаннее, чем они могли бы позволить себе по логике баланса сил при нынешней позиции в экономической, технологической и военной областях. Во-вторых, при, определенной автономизации полюсов в западном мире не просматривается появление новых сколько-нибудь радикальных разделительных линий противоборства между Северной Америкой, Европой и АТР. При некотором возрастании уровня антиамериканской риторики в российской и китайской политических элитах более фундаментальные интересы обеих держав толкают их на дальнейшее развитие отношений с Соединенными Штатами. Расширение НАТО не усилило центростремительные тенденции в СНГ, чего следовало бы ожидать по законам многополюсного мира. Анализ взаимодействия постоянных членов Совета Безопасности ООН, «восьмерки» свидетельствует о том, что поле совпадения их интересов значительно шире области разногласий при всей внешней драматичности последних.

\section{Новые движущие силы мирового сообщества}

Можно предположить, что на поведение мирового сообщества начинают оказывать влияние новые движущие силы, отличные от тех, что традиционно действовали в рамках Вестфальской системы. Для того чтобы проверить этот тезис, следовало бы рассмотреть новые факторы, которые начинают оказывать влияние на поведение мирового сообщества [1, с. 30-33].

Одной из основных характерных особенностей, отличающих международные отношения и современную мировую политику, считается повышение роли новых субъектов международных политических процессов межправительственных, международных и неправительственных организаций - в мировой политике. Принципы, которые некогда считались суверенным правом национальных государств, именуемые в настоящее время государственным суверенитетом, внутренней политикой, отношениями между государством и гражданами, демократией, интересами гражданского общества, защитой прав и свобод человека и другие, постепенно все больше регулируются требованиями и рекомендациями международных структур и неправительственных организаций. В целом, защита и всестороннее соблюдение этих принципов требуются у национальных государств на уровне норм международного права.

Одной из новых форм проявления современных международных отношений можно считать выход на международную арену не только государств, но и отдельных регионов, 
внутренних субъектов стран, их присоединение к международным связям, участие в сотрудничестве. В последнее время такая тенденция получила наиболее широкое распространение в Европе, Юго-Восточной Азии, в ряде случаев связи регионов, представляющих отдельные государства, приобрели значительно более интенсивный характер, чем связи данных государств.

Одним из основных факторов, влияющих на современное состояние международных отношений, можно считать постепенно усиливающуюся мировую интеграцию на фоне активизации в последнее время центробежных процессов (народы, проживавшие в прошлом в едином составе, осуществляют деятельность, направленную на создание своих независимых государств).

Интеграционные процессы, начавшиеся в Европе после Второй мировой войны, за последние десять лет стремительно преодолели межгосударственные границы, и на этом пространстве была сформирована единая стратегия внутренней и внешней политики. Однако некоторая активизация в последние годы центробежных тенденций, этнического сепаратизма, чувства агрессивного национализма и религиозной дискриминации также считаются реалиями современной мировой политики.

Хотя некоторые исследователи утверждали, что окончание «холодной войны» между блоками, представлявшими систему социализма и капитализма, окажет ощутимое влияние на уменьшение конфликтов в мире, тем не менее, данный прогноз не оправдался. Большие государства, прежде всего США и страны Европейского Союза, живущие мечтой о «бесконфликтном мире», прилагают определенные усилия для урегулирования конфликтов с целью спокойного осуществления процесса глобализации. Однако основные причины данных конфликтов, порождающие их субъективные факторы, двойные подходы в применении норм международного права мешают государствам в разрешении этих конфликтов [6, с. 154-155].

Современные конфликты, независимо от причины возникновения, представляют большую угрозу для человечества, охватывают все более обширные территории, вызывают экологические, гуманитарные и социальные катастрофы.

А причины разные. В их числе наиболее часто встречаются территориальные притязания отдельных государств, этнический сепаратизм, противоречия между промышленными государствами и сырьевыми странами, бесконтрольное вооружение, миграция, глобализация, национализм, возникший на почве сопротивления глобализации, и религиозное противостояние.

Если в период противостояния идеологий и блоков международные конфликты, в основном, находились под контролем, использовались целенаправленно, а их глобализация предотвращалась, то на современном этапе механизмы предотвращения подобных конфликтов ослабли. Кроме того, произошедшие в политической системе мира перемены, нарушение сформировавшихся после Второй мировой войны национально-государственных границ также осложнили регулирование конфликтов в соответствии с нормами международного права.

Современные международные отношения и мировая политика - это чрезвычайно сложная система. Число участвующих в данной системе акторов (действующих субъектов) неуклонно растет и расширяется. Если с начала Вестфальской системы до начала XXI столетия в качестве участников международных взаимных связей выступали, в основном, государства и их коалиции, то на современном этапе число акторов данных связей постепенно растет. Среди них особенно выделяются международные структуры, межправительственные и неправительственные организации, транснациональные корпорации и внутригосударственные регионы. Эти акторы, постепенно вытесняя в конце XX - начале XXI столетия национальные государства с мировой арены, овладевают стратегическими рычагами. Играя в современном мире как позитивную, так и негативную роль (международный террор, наркобизнес, религиозный фанатизм и др.), эти структуры вместе с национальными государствами превращаются в основных акторов международных отношений, международного права и глобализации. Таким образом, если прежде международное сообщество ограничивалось межгосударственным взаимодействием, то сейчас они по своему составу представляют собой крайне сложную систему акторов.

Одним из основных акторов современных международных отношений считаются международные межгосударственные и межправительственные организации (ММПО). Возникновение данных организаций началось после Второй мировой войны, которая привела мир в содрогание, и преследовало цель оказать содействие решению стоявших перед государствами общих международных проблем. Первой такой организацией, созданной национальными государствами на основе международного договора, принимавшей непосредственное участие в формировании 
единых для всех стран-членов норм международного права и

принципов взаимодействия и являющейся источником международных правил, считается Организация Объединенных Наций $(\mathrm{OOH})$.

Произошедшие в конце XX- начале XXI века в мире радикальные преобразования требуют пересмотра миропорядка, считавшихся ранее идентичными норм международного права и форм международных отношений. Предпринимаемые попытки устранения социально-экономических и духовнокультурных различий между нациями и государствами, объективные и субъективные условия, результаты данных попыток, в настоящее время требуют пересмотра как теоретических, так и практических вопросов международных отношений. Несоответствия, возникшие между внешнеполитическим поведением некоторых государств и правилами системы международных отношений, достигли на современном этапе такого уровня, который исследователи называют новой мировой реальностью или «миропорядком».

Сущность нового миропорядка заключается в нарушении «многополюсности» в системе международных отношений, где обеспечиваются национальные интересы государств, возникновении «однополюсности», в центре которой находятся США. Если в19451990-х годах в системе международных отношений социалистические и капиталистические ценности, которые провозглашали соответственно СССР и США, определяли общественное поведение стран, народов, объединений людей, основы, цели и задачи государственных строев, то в новом миропорядке этот баланс оказался нарушен. В настоящее время демонстрируется однополюсный подход к развитию мира, межгосударственным отношениям, существующим и желаемым реалиям, целям и задачам деятельности государств, отношениям человек-общество-природа.

\section{Выводы и заключения}

Таким образом, система международных отношений, построенная в XX столетии на основе «многополюсного» влияния на политическое развитие мира и международных отношений, на современном этапе сменилась новым миропорядком. А это, соответственно, меняет не только характер отношений между национальными государствами - основными субъектами международных отношений, но и путь их дальнейшего развития, общественную формацию и оказывает серьезное влияние на ход всемирной истории.
Период истории международных отношений, начиная с Вестфальского (1648) договора до Версальского (1919) соглашения, обладает одним, период, продолжавшийся от Ялтинско-Потсдамской (1945) системы до 1991 года - Беловежского соглашения, - другим, а период, начавшийся с 1991 года - после «холодной войны», - иным характером и правилами.

На современном этапе государства мира по силе влияния на международные процессы и своей роли в международных от-ношениях подразделяются на несколько групп:

- Супердержавы: (эту роль некогда исполняли Великая Римская и Британская империи, СССР и США) страна, обладающая достаточным военным, экономическим, культурным потенциалом для обеспечения своих национальных интересов на всем Земном шаре, требующая от других государств мира учитывать ее интересы и интересы еe союзников и добивающаяся этого, считается супердержавой. В настоящее время эта роль принадлежит лишь США.

- Крупные государства: сюда входят страны, способные обеспечить свои национальные интересы в собственной стране, регионе и других важных регионах мира (не во всем мире), могущие заставить другие страны считаться с ними (Англия, Япония, Франция, Германия и др.). Россия в настоящее время ведет борьбу за то, чтобы войти в это число.

- Региональные государства: страны, способные обеспечить и защитить собственные интересы в своей стране и регионе, на прилегающих к их границам территориях. Эти страны не могут оказать серьезного сопротивления в дальнем зарубежье, но способны на это в своем регионе (Китай, Иран, Россия, Турция, Пакистан, Египет и др.).

- Обычные государства: эти страны, как могут, обеспечивают свои национальные интересы внутри, в регионе и мире [6, с. 171-172].

Вероятность обеспечения их интересов, как правило, возрастает, если они приводятся в соответствие с интересами первых трех групп.

На протяжении истории существования системы международных отношений силовые центры в мире, меняясь в форме многополюсного (несколько центров), двухполюсного (два центра) и однополюсного (один центр) силового баланса, пришли к нынешней системе, именуемой «новый миропорядок».

Одна из отличающих новый миропорядок главных особенностей заключается в том, что все государства и народы, независимо от того, на какой иерархической ступени они находятся, постепенно обретают равное положение перед 
глобальными проблемами, несут одинаковую ответственность за судьбу планеты, а значит, в осознании глобальной общности человечества.

Кроме того, на современном этапе основные права и свободы человека, фундаментальные принципы отношений гражданин-государствообщество, такие вопросы как устранение конфликтных ситуаций уже расцениваются не как внутреннее дело отдельных государств, а как дело организаций, защищающих нормы международного права в целом, что также считается особенностью, характеризующей новый миропорядок.

Другой постулат, определяющий качественную характеристику нового миропорядка, заключается в том, что он зиждется на капиталистических производственных отношениях. Победа Запада в глобальном противостоянии капитализма и социализма, возникшем после Второй мировой войны, распад социалистического лагеря и СССР способствовали провозглашению капитализма, олицетворяющего рыночные отношения, безальтернативной экономической основой миропорядка. А это, соответственно, дало государствам, которые недавно обрели независимость, основание выбрать именно капиталистическую систему как единственное условие развития и материальной основы демократизации.

Одной из характерных особенностей нового миропорядка можно считать постепенную либерализацию международными объединениями, организациями социальнополитической ориентации как основы системы международных отношений. Такие понятия как фашизм, социализм, которые некогда нашли себе партнеров в мире и превратились в основной идеологический принцип определенных государств, постепенно уступают

место либерализму. Правда, сегодня человечество в определенной мере обеспокоено также широким распространением в мире национализма и религиозных идей. Однако идеология либерализма, полностью утвердившаяся в экономической, политической и духовной жизни Запада и достаточно популярно пропагандируемая в мире как идея, сегодня расценивается как непреходящая ценность нового миропорядка.

Самый спорный вопрос нового миропорядка - это вопрос о том, кто регулирует современные международные отношения

межгосударственные правила - международные организации или постепенно стремящиеся к гегемонии США. Американские политологи считают, что современный мир «нуждается в просветительском руководстве», и такую роль могут сыграть именно США. По их мнению, место и роль США в современной мировой экономике и политике позволяют им взять на себя мировое лидерство, обеспечить мир, безопасность и спокойствие на планете. Они считают, что военный, экономический, политический, социальный и культурный потенциал США полностью отвечает этому.

Есть и другие мнения. В качестве примера можно привести Китай, Россию и считающихся западноевропейскими союзниками США Францию и Германию. Эти страны считают, что новый миропорядок требует коллективной ответственности, коллективного вмешательства. Поэтому международные отношения должны найти свое решение в рамках $\mathrm{OOH}$, ее Совета Безопасности, по всем вопросам необходимо совместное согласие [6, с. 173-174].

Важное значение в условиях нового миропорядка в международных отношениях представляют проблемы геополитики, регионализации и региональной интеграции, процессы глобализации.

В настоящее время геополитический подход к новому миропорядку считается одним из самых актуальных вопросов на международной арене. Политологи мира в числе геополитических реалий системы международных отношений особо исследуют борьбу противостоящих друг другу морской (США и их союзники по НАТО) и сухопутной (Китай, России, Индия) цивилизаций. По мнению исследователей, ввиду того, что Китай, Россия и Индия не смогли создать между собой ни идеологического, ни институционального базиса, морская цивилизация доминирует во всем мире, в том числе в Евразийском регионе, ЮгоВосточной Азии.

Одними из характерных особенностей нового миропорядка считаются постепенное обретение глобализацией более широкого размаха, распространение всем мире западных ценностей, стирание национальных границ между государствами, нациями и культурами, единение мира. Хотя процесс единения мира, именуемый в научной литературе как «мондиализм», в целом, является объективным, в действительности же это глобальный, но субъективный процесс, планируемый, регулируемый и управляемый США и их союзниками. Несмотря на то, что исследователи расценивают глобализацию как объективный процесс, тем не менее, они считают «мондиализм» (внедрение западных ценностей во всем мире) продуманным сценарием, когда сухопутную цивилизацию, в целом, все относительно слабо развитые государства мира силой заставляют принять морскую цивилизацию, сценарием с фатальным финалом. Оценивая перспективу внедрения западных ценностей в остальные части мира, они 


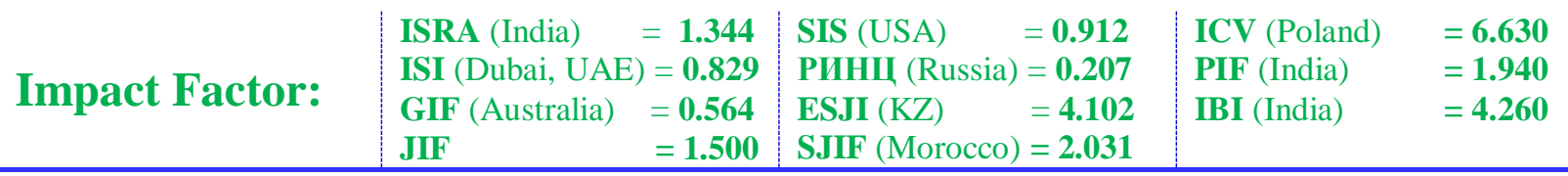

прогнозируют, что в дальнейшем «единый мир будет формироваться как возросшая проекция США» [6, с. 175].

Новый миропорядок обусловлен нарушением сформировавшейся в рамках $\mathrm{OOH}$ системы, связанной с вопросами военного баланса и коллективной безопасности. Некогда главенствовавший в мире баланс военных сил, противостоявшие друг другу военные блоки (НАТО и Организация Варшавского Договора) уступили свое место США и их союзникам по HАTO. Государства, представляющие в настоящее время данный лагерь, обладают возможностями военного вмешательства и военного влияния на всех территориях мира.

Идеологические устои нового миропорядка обосновываются тем, что западный образ жизни, западные духовные ценности являются привлекательными, передовыми, гуманными и либеральными. А это с помощью средств глобализации, универсализации и духовной интеграции используется для воспитания, духовного обогащения людей во всем мире в соответствии с данными ценностями.

\section{References:}

1. (1999) Sovremennyie mezhdunarodnyie otnosheniya. Uchebnik / Pod. red. A. V. Torkunova. M.: «Rossiyskaya politicheskaya entsiklopediya» (ROSSPEN), 1999. -584 p.

2. Karimov I.A. (1992) Uzbekistan: svoy put obnovleniya i progressa. T.: «Uzbekistan» 1992. $-71 \mathrm{p}$.

3. Azizhonov A.T., Efimova L.P. (2005) Teoriya i praktika stroitelstva demokraticheskogo obschestva v Uzbekistane. T. 2005. -372 p.

4. Karimov I.A. (1999) Svoe buduschee myi stroim svoimi rukami. T.: «Uzbekistan» 1999. 382 p.

5. Mackinder N. (1904) Geographical Pivot of History // Geographical Journal. 1904. №2. -p. 75-79.
6. Gasanov A. (2007) Sovremennyie mezhdunarodnyie otnosheniya i vneshnyaya politika Azerbaydzhana. B.: «Shark-Garb». 2007. -904 p.

7. (2000) Vyistuplenie Prezidenta Azerbaydzhanskoy Respubliki Geydara Alieva na Sammite tyisyacheletiya v Nyu-Yorke 7 sentyabrya 2000. // Bakinskiy rabochiy, ot 20 sentyabrya 2000.

8. Huntington S.P. (1996) The Class of Civilization and the remaking of World Order. New York.

9. Rahimov M. (2011) Mezhdunarodnoe sotrudnichestvo Uzbekistana v kontekste obespecheniya stabilnosti i ustoychivogo razvitiya v Tsentralnoy Azii. T.: «Yangi nashr». 2011. $-232 \mathrm{p}$ 